\title{
Assessment of disturbed voltage supply effects on steady-state performance of an induction motor
}

\author{
Jamal Abdul-Kareem Mohammed ${ }^{1}$, Sahar R. Al-Sakini' ${ }^{2}$, Arkan Ahmed Hussein ${ }^{3}$ \\ ${ }^{1,2}$ Departement of Electromechanical Engineering, University of Technology, Baghdad, Iraq \\ ${ }^{3}$ Departement of Electrical Engineering, Tikrit University, Baghdad, Iraq
}

\begin{tabular}{l} 
Article Info \\
\hline Article history: \\
Received Mar 8, 2019 \\
Revised Nov 23, 2019 \\
Accepted Nov 30, 2019 \\
\hline Keywords: \\
Induction motor \\
Steady-state performance \\
Symmetrical components \\
Voltage disturbance \\
Voltage unbalance factor
\end{tabular}

\begin{abstract}
An electric power system is usually exposed to unequal and variable loads across its three phases, which leads to voltage unbalance and variation, making the three-phase voltages asymmetrical in nature at the distribution end. This problem is clearly evident in Iraq country, particularly with regard to the fluctuating voltage levels of electricity distribution during peak hours. Providing a three-phase motor with asymmetric voltages is badly affecting its working performance. Estimating the performance of this motor at steady-state under different conditions of voltage disturbances is investigated in this paper through Matlab simulation using Symmetrical component approach. The motor performance represented by active and reactive input powers, output put power, developed torque, power losses, efficiency and power factor is analyzed under full load conditions. Also, the steady-state power losses- and torque-slip characteristics at certain degrees of voltage unbalance have been calculated and plotted.
\end{abstract}

Copyright $@ 2020$ Institute of Advanced Engineering and Science. All rights reserved.

\section{Corresponding Author:}

Jamal Abdul-Kareem Mohammed,

Department of Electromechanical Engineering,

University of Technology, Baghdad, Iraq.

Email: 50128@uotechnology.edu.iq

\section{INTRODUCTION}

Power quality is an issue to which electrical engineers have to pay special attention. It is very common to find problems of power quality in electric supply systems, among these problems, the voltage disturbances which include voltage balance and unbalance [1]. The voltage unbalance is a global phenomenon, known almost anywhere in the three-phase system around the world. In spite of the three-phase supply voltages at the generation and transmission levels are entirely balanced in both quantity and angle, it is not so at utilization end because of unequally distribution of loads, inefficient energy transferring of transmission lines, blowing fuses that protect capacitor bank, defective transformers, etc. The unbalance in voltages has many bad effects on the supply system in addition to the consumer. It has proved very effective in the deteriorating performance of electrical equipment, e.g. on induction motors IMs at the user end.

The IMs are the most commonly used in power industries, due to its simple, rugged, low price maintenance, easy to control and excellent operating characteristics. These motors consume approximately $68 \%$ of the electricity utilized in the industry worldwide [2]. As an approximate estimate, about $80 \%$ of the world's industrial motors used are three-phase IMs [3]. Performance analysis of the IM operation plays an important role in the design of a convenient protection system and identifies opportunities for saving energy. This motor is designed to operate under balanced three-phase voltage condition, but a small amount of voltage unbalance that is caused by the introduction of a negative-sequence voltage may increase the current very substantially, causing an increase in power losses and a decrease in efficiency, developed torque, and insulation lifespan. The increased losses may cause over-heating the motor and hence burning. 
Several previous studies have been done in an effort to determine the impact of the imbalance in supply voltage on the IM performance characteristics. Kersting and Phillips [4] had discussed the influence of $0-5 \%$ voltage unbalance on the power losses that result in an IM. They concluded that the unbalance degree and unbalancing method has a significant impact on permissible machine load. The effect of the positive sequence voltage on the performance of three-phase IMs had been reported by Lee [5], Mendes et al. [6] and Quispe et al. [7]. They had concluded that a higher positive-sequence voltage will lead to a higher motor efficiency and a lower power factor as well as the behavior of the positive sequence voltage should be taking into consideration along with the percent voltage unbalance PVU index in order to protect the motor from overheating. A summary of the literature on the impact of unbalanced supply voltage on IMs was offered by Reineri et al. [8]. They carried out an experimental study, where rotor currents of an IM were measured in different conditions of imbalance in relation to positive and negative sequence voltage quantities and phase angles. They found that the rotor overcurrent does not depend on the angle of the positive-to-negative sequence components.

The negative impact of the unbalanced voltage of power supply upon power losses and efficiency of a three-phase IM was studied by Faiz et al. [9]. They identified the financial losses resulting from unbalanced voltage using a statistical analysis method. Dymond and Stranges [10] carried out tests using time-stepping finite-element for measuring and testing of an IM at three different levels of unbalanced voltage to demonstrate their effect on stator and rotor heating, speed-torque, and locked rotor performance as well as noise, vibration, and shaft voltage. Farahani et al. [11] constructed a rotor and stator monitoring system under different types of imbalance, applied on an IM to investigate their influence on the temperature rise. It was found that the increase in motor temperature depends on the positive, negative and zero sequence voltages. Gnacinski [12] investigated the effect of the complex voltage unbalance factor CVUF angle on the winding's temperature rise and the derating factor of an IM fed from unbalanced voltages. The effect of simultaneous voltage unbalance and harmonics on the motor operational life was also analyzed.

The effects of voltage unbalance on the oscillation of motor power, torque and vibrations were extensively analyzed by Bossio et al. [13]. They deduced that voltage unbalance can produce a torque oscillation and a significant increase of the motor vibrations. Mirabbasi et al. [14] investigated the negative effects of unbalanced sinusoidal voltage in the power supply on the performance of an IM in terms of line currents, power factor, and efficiency. Neves et al. [15] presented a theoretical and experimental analysis of the voltage unbalance effects on the torque and efficiency in a three-phase IM. It was found that the imbalance in voltage magnitudes have noticeable effects on the torque and efficiency of the motor. Gupta et al. [16] adopted the current unbalance factor CUF in evaluating the negative effects of the unbalance supply voltage for calculating the various normalized performance parameters of a three-phase IM. Also, they highlighted the need to include the current based index instead of voltage-based index.

In the last years, steady-state analysis of an IM under the effect of unbalanced voltage had been quite well documented in the literature. Fernández et al. [17] presented the development of a thermal monitoring system to study the thermal steady-state behavior of IMs under the influence of unbalanced supply. Wang [18] analytically investigated the impact of voltage unbalance on the steady-state performance of an IM, depending on the index CVUF. He had proved that the voltage unbalance can cause significantly unbalanced motor line currents. Wang [19] presented an analytical method to evaluate the impact of voltage unbalance on the load carrying capacity of an IM at steady-state by using CVUF. Faiz et al. [20] had studied the adverse impacts of a specific unbalanced voltage on the steady-state performance of an IM. They analyzed various definitions according to the standards and proposed that the available definitions of voltage imbalance are not complete and comprehensive, and have unreliable results. Huang and Wang [21] utilized the circle diagram method for analyzing the steady-state performance of a three-phase IM under voltage unbalance. Sandhu and Chaudhary [22] described a method depend on the symmetrical component theory in order to analyze the steady-state operation of a three-phase IM, working under an unbalanced voltage supply system. The performance of a three-phase IM supplied by an unbalanced voltage source had been analyzed by Jalilean and Roshanfekr [23], when the variations of motor stator current, efficiency, rotor ripple, and power factor had been studied under different conditions of steady-state unbalanced voltage. It was found that the stator CUF and power losses would increase (efficiency decreases) as voltage unbalance factor VUF increases under constant load conditions. Eftekhari and Sadegh [24] had introduced an optimum phase-balancing technique and discussed the impact the modelling of load on phase-balancing studies. They used the re-phasing method and harmony search algorithm to balance a distribution network for optimizing the phase-displacement process.

Most of the previous studies had concentrated on the voltage unbalances that result from under voltage. Over voltage cases are often occurring at peak times, especially in countries experiencing significant quality problems in power systems such as Iraq, regarding the fluctuating voltage levels of electricity distribution [25]. Accordingly, this paper deals with the estimation of a three-phase IM performance, working at steady-state under full load conditions for different cases of expected voltage disturbances that might be 
occurred in Iraq country, such as under/over and unbalanced/balanced voltage disturbances at different values of VUF. Also, the steady-state performance characteristics, related to power losses- and torque-slip have been calculated and plotted through simulation under different voltage magnitude unbalance conditions. A method based on the symmetrical component theory has been employed to analyze the operations of the three-phase IM under the conditions of voltage disturbances.

\section{TYPES OF VOLTAGE UNBALANCE}

Because of the different runtimes of single-phase and three-phase loads at the utilization end of a power system, there exists a definite possibility of voltage variations below and above the rated value, in both balanced and unbalanced forms. Thus, voltage variation and unbalance can be classified into, under voltage unbalance (UVU), over voltage unbalance (OVU), under voltage balance (UVB) and over voltage balance (OVB) [5, 26, 27]. The UVU represents the condition of inequality of the three-phase voltages, as well as, the positive sequence voltage component is lesser than the rated voltage value, whereas the OVU is the condition of unequal three-phase voltages, and the positive sequence voltage component is higher than the rated voltage value. The UVB happens when the three-phase voltages are equally and individually smaller than the rated value, while the OVB is occurring when the three-phase voltages are equally and individually greater than the rated value. There is a very low probability that all three-phase voltages stay balanced over time. The unbalanced cases that have been studied in this paper are:

- Single phase UVU: If the power system has a heavy single-phase load and has no adequate compensation, the voltage in this phase will be less than the other two phases.

- Two phases UVU: If two phases in the system have large loads and there is no adequate compensation, the voltages at these phases will be less than the third phase.

- Three phases UVU: It is most common unbalance, occurs when the three phases have very big loads.

- Single phase OVU: To keep the voltage system at the rated value, capacitors are normally utilized for compensating the reactive power system. The single-phase OVU occurs when one of the three phase voltages are overcompensated, so it becomes higher than the rated value.

- Two phases OVU: It occurs if two phases are overcompensated and their voltages are unequal and higher than the rated value.

- Three phases OVU: It occurs when the three phases are differently overcompensated, so they become unequal and greater than the rated value.

\section{DEFINITION OF VOLTAGE UNBALANCE}

There are two common definitions of voltage unbalance; they are as follows [28]:

\subsection{NEMA (IEEE) definition}

The voltage unbalance percentage (VUP) on machine terminals as offered by the National Electrical Manufacturer Association Motor and Generator Standard (NEMA MGI) is:

$$
\operatorname{VUP}(\%)=\frac{\text { Max. voltage deviation from average voltage }}{\text { average voltage }}
$$

the NEMA definition adopts line voltages while IEEE offers another similar definition uses phase voltages.

\subsection{IEC or symmetrical component definition}

It is given by International Electrotechnical Commission (IEC) as a voltage unbalance factor (VUF) and defined as the ratio of negative-sequence voltage component to positive-sequence voltage component.

$$
\operatorname{VUF}(\%)=\frac{V_{n}}{V_{p}} \times 100
$$

These components can be obtained by symmetrical component transformation. This definition gives a more accurate assessment of the voltage unbalance because it also evaluates the negative-sequence voltage.

\section{STEADY-STATE ANALYSIS}

Under real operating conditions, the supply voltage is far from being perfect and balanced. It is assumed in this study that though the supply is sinusoidal, it is exposing to voltage balanced/unbalanced disturbances, given as a percentage of VUF. The steady-state model of a three-phase IM operating under 
voltage disturbances is possible to be analyzed by means of symmetrical component approach. Therefore, representation development of per phase positive and negative sequence equivalent circuits [18] is demonstrated in Figure 1. These circuits are required to estimate the behavior of the positive and negative sequence components of the supply voltage disturbance to perceive their impact on the IM and compute the steady-state performance of the essential parameters of the motor such as; active and reactive input powers, output put power, developed torque, power losses, efficiency and power factor.
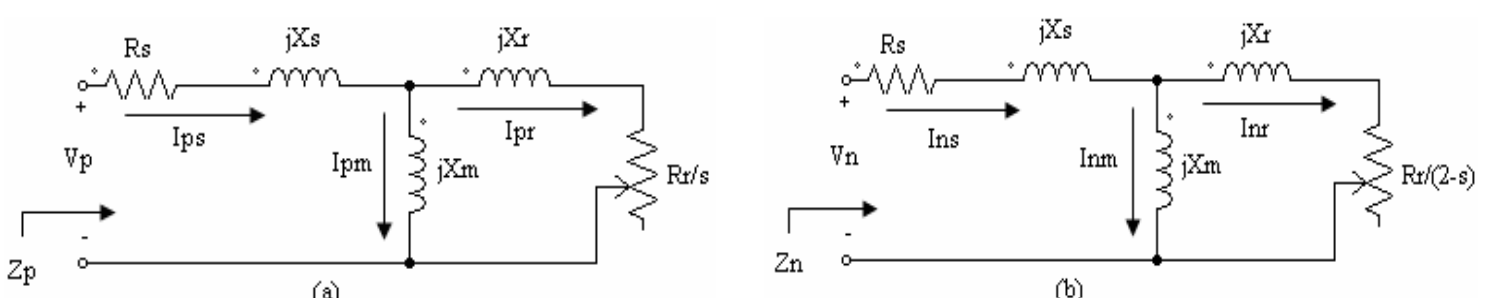

Figure 1. Per-phase motor equivalent circuits, (a) positive-seq. (b) negative-seq

The voltage of the positive sequence component yields a positive torque; while the negative sequence component voltage produces an air gap flux rotates in the opposite direction to the main magnetic field, which generates a harmful reverse torque. So, actually, when ignoring the non-linearity, for example, because of saturation phenomenon, the motor acts like a superimposition of two separate motors, one works with a terminal voltage per phase $V_{p}$ at a slip of $s$ and the other works with a terminal voltage of $V_{n}$ at a slip of 2-s. Because of the negative sequence impedance $\left[R_{r} /(2-s)\right]$ is low, the negative sequence voltage raises significant negative sequence currents. At normal rated running speeds, the unbalanced voltages produce unbalanced line currents, more than 6 to10 times those voltages. The per-phase values demonstrated in Figure 1 might be given as follows:

$V_{p}, V_{n}$ positive and negative-sequence voltages

$R_{s}, X_{s} \quad$ effective stator resistance and reactance

$R_{r}, X_{r} \quad$ stator resistance and reactance referred to the rotor

$X_{m} \quad$ magnetization reactance

$Z_{p}, Z_{n} \quad$ positive and negative-sequence impedances

$I_{p s}, I_{n s} \quad$ positive and negative-sequence stator currents

$I_{p r}, I_{n r} \quad$ positive and negative-sequence rotor currents

$I_{p m}, I_{n m}$ magnetization branch positive and negative-sequence currents

$s \quad$ operating slip

Assuming that $V_{a}, V_{b}$, and $V_{c}$ are the phase voltages feeding the IM. Correspondingly, the zero, positive, and negative-sequence voltage components $\left(V_{0}, V_{p}\right.$, and $\left.V_{n}\right)$ might be written as $[18,20,23]$ :

$$
\left[\begin{array}{l}
V_{0} \\
V_{p} \\
V_{n}
\end{array}\right]=\frac{1}{3}\left[\begin{array}{ccc}
1 & 1 & 1 \\
1 & a & a^{2} \\
1 & a^{2} & a
\end{array}\right]\left[\begin{array}{c}
V_{a} \\
V_{b} \\
V_{c}
\end{array}\right]
$$

where: $a=1 \angle 120^{\circ}$. Analyzing the equivalent circuit of the motor leads to:

$$
Z_{i}=R_{s}+j X_{s}+\frac{\left(j X_{m}\right)\left(\frac{R_{r}}{S_{i}}+j X_{r}\right)}{\frac{R_{r}}{S_{i}}+j\left(X_{m}+X_{r}\right)}
$$

for positive-sequence impedance, $i=p$ and the motor slip is $s_{p}=s$, and for negative-sequence impedance, $i=n$ and the slip is $s_{n}=2-s$. The positive- and negative-sequence currents of the stator and rotor respectively are:

$$
\begin{aligned}
& I_{p s}=\frac{V_{p}}{Z_{p}} \\
& I_{p r}=I_{p s} \times \frac{j X_{m}}{\frac{R_{r}}{s}+j\left(X_{m}+X_{r}\right)}
\end{aligned}
$$




$$
\begin{aligned}
& I_{n s}=\frac{V_{n}}{Z_{n}} \\
& I_{n r}=I_{n s} \times \frac{j X_{m}}{\frac{R r}{2-s}+j\left(X_{m}+X_{r}\right)}
\end{aligned}
$$

assuming that the motor windings are delta or ungrounded wye connected, therefore:

$$
\begin{aligned}
& I_{a s}=I_{p s}+I_{n s} \\
& I_{b s}=a^{2} I_{p s}+a I_{n s} \\
& I_{c s}=a I_{p s}+a^{2} I_{n s}
\end{aligned}
$$

the motor active input power $P_{i n}$ and reactive input power $Q_{i n}$ respectively may be expressed by the symmetrical voltage and current components as follows:

$$
\begin{aligned}
& P_{i n}=\operatorname{Re}\left[3\left(V_{p} I_{p s}^{*}+V_{n} I_{n s}^{*}\right)\right] \\
& Q_{i n}=I_{m}\left[3\left(V_{p} I_{p s}^{*}+V_{n} I_{n s}^{*}\right)\right]
\end{aligned}
$$

where indicates the conjugate value. The motor power factor might be given as:

$$
P_{f}=\cos \left[\tan ^{-1}\left(Q_{\text {in }} / P_{\text {in }}\right)\right]
$$

by neglecting the mechanical losses and core losses, the output power resulting from the positive and negative-sequence components, respectively could be given as:

$$
\begin{aligned}
& P_{p}=3 I_{p r}^{2}\left(\frac{1-s}{s}\right) R_{r} \\
& P_{n}=3 I_{n r}^{2}\left(\frac{s-1}{2-s}\right) R_{r}
\end{aligned}
$$

thus, the output power will be:

$$
P_{\text {out }}=P_{p}+P_{n}=3(1-s) R_{r}\left[\frac{\left[I_{p r}^{2}\right.}{s}-\frac{I_{n r}^{2}}{2-s}\right]
$$

where, $P_{n}$ has negative value at rated slip, since the rotor spins in the opposite direction of the magnetic field, yielding from the negative-sequence component. Motor torques generated by the positive and negative-sequence current components respectively might be given as:

$$
\begin{aligned}
& T_{p}=\frac{P_{p}}{\omega_{m}}=\frac{P_{p}}{\omega_{s}(1-s)}=\frac{3 I_{p r}^{2} R_{r}}{s \omega_{s}} \\
& T_{n}=\frac{P_{n}}{\omega_{m}}=\frac{P_{n}}{\omega_{s}(1-s)}=\frac{3 I_{n r}^{2} R_{r}}{(2-s) \omega_{s}}
\end{aligned}
$$

where, $\omega_{m}$ and $\omega_{s}$ are the rotor's angular and synchronous speeds, respectively. The presence of negative sequence currents due to unbalanced voltage creates a negative sequence torque which is subtracted from the positive sequence torque to yield a net output developed torque under unbalanced supply, as given by:

$$
T_{d}=T_{p}+T_{n}=\frac{3 R_{r}}{\omega_{s}}\left(\frac{I_{p r}^{2}}{s}-\frac{I_{n r}^{2}}{2-s}\right)
$$

also, the motor power losses $P_{\text {loss }}$ and efficiency $\eta$, respectively can be obtained as:

$$
\begin{aligned}
& P_{\text {loss }}=P_{\text {in }}-P_{\text {out }} \\
& \eta=\frac{P_{\text {out }}}{P_{\text {in }}} \times 100 \%
\end{aligned}
$$




\section{RESULTS AND DISCUSSION}

Matlab simulation is developed based on the symmetrical components approach to analyze and estimate the steady-state performance of a three-phase IM at various operating conditions of voltage disturbances. To conduct this study, a three-phase IM model was carried out with the following parameters: $10 \mathrm{HP}, 230 \mathrm{~V}, 50 \mathrm{~Hz}$, 4-poles, $1440 \mathrm{rpm}, R_{s}=0.7384 \Omega, R_{r}=0.7422 \Omega, X_{s}=X_{r}=0.9425 \Omega, X_{m}=38.987 \Omega$ and nominal slip $s=0.04$. In this model, the components of the motor circuit are assumed to be constant.

\subsection{Steady-state motor performance analysis under unbalanced voltage supply}

Cases of voltage unbalance disturbances regarding the under voltage UVU and over voltage OVU are suggested to occur on single, two or three phase voltages and feed the three-phase IM. These voltages have been applied on the IM model to simulate its steady-state performance and the results are graphically demonstrated as in the curves (a-j) of Figure 2. A comparative study of the motor performance parameters can be drawn from those curves in the steady-state and under the full load when the input terminals of the motor are exposing to different voltage unbalance conditions. Those parameters are including the per unit values (i.e. rated slip $s_{r}$ and pullout slip $s_{m}$, input active power, input reactive power, power losses, output power, developed torque, efficiency, power factor, starting torque $T_{s}$, and pull out torque $T_{m}$ ).

Increasing the drop of phase voltages under the nominal value of $230 \mathrm{~V}$ or increasing the rise of phase voltages over the nominal value causes an increase in the degree of voltage unbalance VUF. The variation of the VUF shown in Figure 2 is considered up to $20 \%$, so as to observe the effect of the voltage unbalance above the recommended NEMA range of (0-5\%). Initially, the motor slip values should be calculated in order to assess the motor performance parameters. Therefore, the per unit values of the rated slip $s_{r}$ and the pullout slip $s_{m}$ of the IM have been found when single, two or three of its phases are exposing to different voltage unbalance disturbances across the specific range of the VUF, as shown in Figure $2(a, b)$.

The full load torque is still demanded to be constant at a certain value of 47.8 N.m. (1p.u.), then the motor under the lower phase voltages (UVU faults) will be forced to operate at slip values higher (lower speeds) than the nominal value (1p.u.) and these values increase with the increase of the fault degree (VUF), while the motor will run at lower slip values (higher speeds) under the higher phase voltages (OVU faults) and decrease with the VUF as shown in Figure 2(a). It can see that increasing the number of failed phases would increase the slip values under the UVU case of disturbance while they would decrease them under the OVU case. The same scenario applies to the pullout slip $s_{m}$ shown in Figure 2(b). In general, the slip values $\left(s_{r}\right.$ and $\left.s_{m}\right)$ of the IM are inversely proportional to the value of the applied phase voltages. Therefore, it is shown from Figure 2, that the slip curves ( $a, b)$ under the UVU faults are located above the OVU curves. So, it can conclude, the motor slip (or speed) values are greatly affected (increase or decrease) when all the three phases of the motor are subjected to voltage unbalance disturbance in comparison with single phase or two phases of unbalance. The curves also show that the rated slip (or speed) values are more affected by the UVU disturbances than the OVU ones, and vice versa in the case of the pullout slip. As a result of all the foregoing, in both unbalance fault cases, the increase in the VUF values will lead to increasing the negative-sequence current and associated power losses of the motor as shown in Figure 2(e) and thus, increase in the heat dissipation over their nominal values. Therefore, the IM during unbalanced voltage operations dissipates additional active power from the voltage supply (Figure 2(c)).

The variations in the input active power and power losses of the IM are obtained according to the slip values for different ratios of VUFs under different conditions of phase voltage unbalance as respectively illustrated in the curves (c, e) of Figure 2. It is observed form these curves that the input power and power losses are increasing with the VUF under all voltage disturbance conditions. This will increase the input power absorbed by the power losses which are primarily responsible for heating the motor and adversely affect its insulation, in addition to the extra costs the customer will pay because of the energy consumed by those losses. Thus, the power losses are playing an important role in the study of IM performance. Also, it is noted that the motor losses are increasing with the increase of the number of failed phases for all voltage unbalance conditions, while the input power is decreasing under the UVU disturbance and increasing under the OVU one with the number of failed phases.

On the other side, Figure 2(d) show how the input reactive power increases under the OVU faults with the VUF and the number of failed phases, and approximately constant under the UVU faults, while under the same conditions, the input active power increases. This will cause the motor power factor according to (12) to drop in the OVU disturbances and almost constant in the UVU as shown in Figure 2(h). It is seen that the power factor is slightly increased with the increase of the number of phases subjected to UVU disturbances while it is significantly decreasing under the OVU cases. The decrease in the power factor is resulting from the increase rate of the reactive power input to the motor relative to the active power. Hence, the higher supply voltage (higher VUF under OVU) is badly affecting the power factor and the required reactive power. Also, the more increase in the reactive power with the VUF under OVU disturbances means that the motor 
subjected to this disturbance will draw extra reactive power and as a result power quality problems will appear on the utility network.

It is observed from Figure 2(f) that the output power curves slightly increase with the VUFs and the number of failed phases under the OVU fault, while they highly decrease under the UVU fault. It can be noticed that the rising rate in the output power under the OVU disturbance is less than the drop rate under the UVU case. Also, it is observed by comparing the input and output power curves (c, $\mathrm{f}$ ), the increase rate in the output power under OVU fault is lower than that of the input power. Also on another side, under the UVU case, the output power decreases while the input power increases. This causes, in both cases, the motor efficiency shown in Figure 2(g) to decrease from its rated balanced value with the VUF and the number of motor phases exposing to fault under all conditions of voltage unbalance. In other words, the higher the voltage unbalance, the more decrease in efficiency. The reduction of the efficiency with the VUF is due to the increase of negative torque component as well as the excessive losses created in the IM under the voltage unbalance. It is noted from the figure that the efficiency curves under the OVU locate above the UVU ones within the VUF range of about (0-10\%), and this situation is reversed after this range. This means that the motor has higher efficiency under the OVU conditions than the UVU at the lower degrees of VUF.

The curves ( $\mathrm{i}$ and $\mathrm{j}$ ) in Figure 2, respectively demonstrate the per unit ratios of the motor starting torque $T_{s} / T_{r}$ and pullout torque $T_{m} / T_{r}$ relative to the rated torque. It can see, under the UVU disturbances that the starting torque ratio increases with the VUF and the number of failed phases, while the pullout torque ratio decreases with them. On the other side, under the OVU disturbances, the starting torque ratio decreases with the VUF and the number of failed phases, while the pullout torque ratio increases with them. This means that the motor requires more starting torque under lower phase voltages, increases with the increase of the number of the motor phases subjected to UVU disturbance, while it needs less starting torque when the motor phases subjected to higher voltages, decreases more with the increase of the number of phases subjected to OVU disturbance. As for the pullout torque, the motor could provide more pullout torque with higher phase voltages, increases with increasing the number of failed phases, while the motor produces less pullout torque under lower phase voltages, decreases with the number of failed phases.

\subsection{Performance characteristics under voltage disturbances}

The motor performance parameters do not depend solely on the VUF degree, but also on the slip information needed for reliable and accurate assessment of these parameters. Under the rated voltage balance VB conditions (healthy case), the proposed motor was found to be working at a rated slip $s_{r}$ of 0.04 (1 p.u.), at which the motor develops its rated torque. The Figures 3-6 demonstrate the steady-state torque-slip and power losses-slip characteristics at certain values of VUF $(0,3,6$, and $9 \%)$ when the motor is subjected to different conditions of voltage balanced/unbalanced disturbances on single, two or three of its input terminals. The vertical axis of these characteristics is the developed torque or power losses which are normalized with regard to the corresponding motor rated values. Figure 3 demonstrates how the torque-slip and losses-slip curves under the balanced voltage disturbances drop with the decrease of supply voltages (UVB) under the nominal value (VB) of $230 \mathrm{~V}$, while these curves elevate by increasing the supply voltages (OVB) over the nominal value. It can be shown that all the torque curves in the UVB and OVB disturbances can meet the demands of the rated torque load unless the UVB curve at $115 \mathrm{~V}$.

On the other side, the Figures 4-6 illustrate how the torque-slip and losses-slip curves drop with the decrease of supply voltages under the nominal value (increase VUF) and the number of motor phases subjected to voltage UVU disturbances, while these curves elevate by increasing the supply voltages over the nominal value (increase VUF) and the number of the motor failed phases under the OVU disturbances. The reduction in motor devolved torque shown in the Figures 3-6 are caused by the reverse air gap field (MMF) produced by the negative sequence currents. It is noted that the existing voltage disturbances on the terminals of the motor result in changing the torque-slip characteristics and thus, changing the motor operating point. It is shown how the slip at the rated torque (1 p.u.) slightly increases with the VUF under the UVU fault while decreases under the OVU fault although the shaft torque of the motor is preserved when fully loaded. Also, it can be deduced from the losses and torque characteristics that the impact of the voltage disturbances on increasing losses is much higher at high loads (higher slip values).

The shape of the torque-slip characteristics over the remaining operating part has changed drastically; the pull-out torque has greatly decreased with the VUF under the UVU fault and greatly increased under the OVU fault, the point at which higher pullout torque occurs moves to a higher slip value. The figures indicate the variation ranges of the starting and the pull-out torques with the VUF's are significant, while the variations of the rated torque around the motor's running point are negligible. 

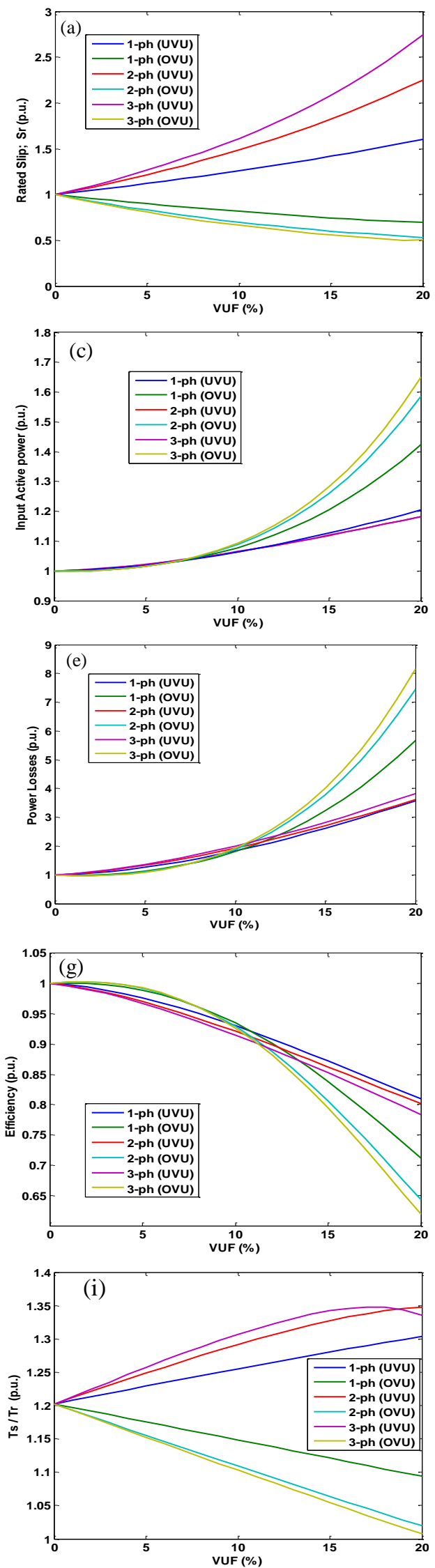
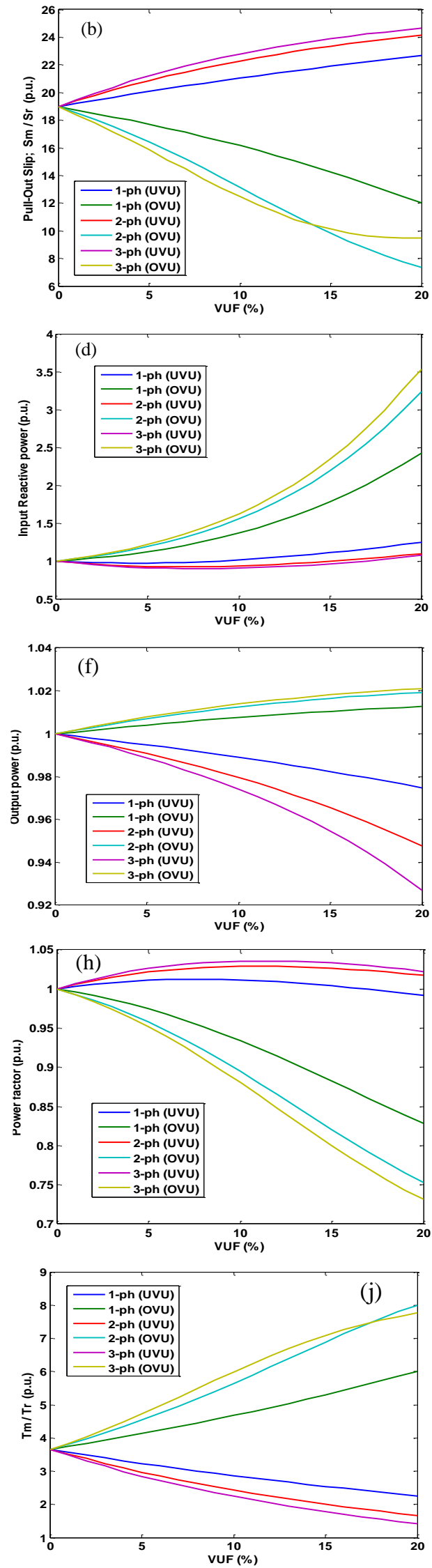

Figure 2. Motor performance under full-load and different conditions of voltage unbalance disturbance 

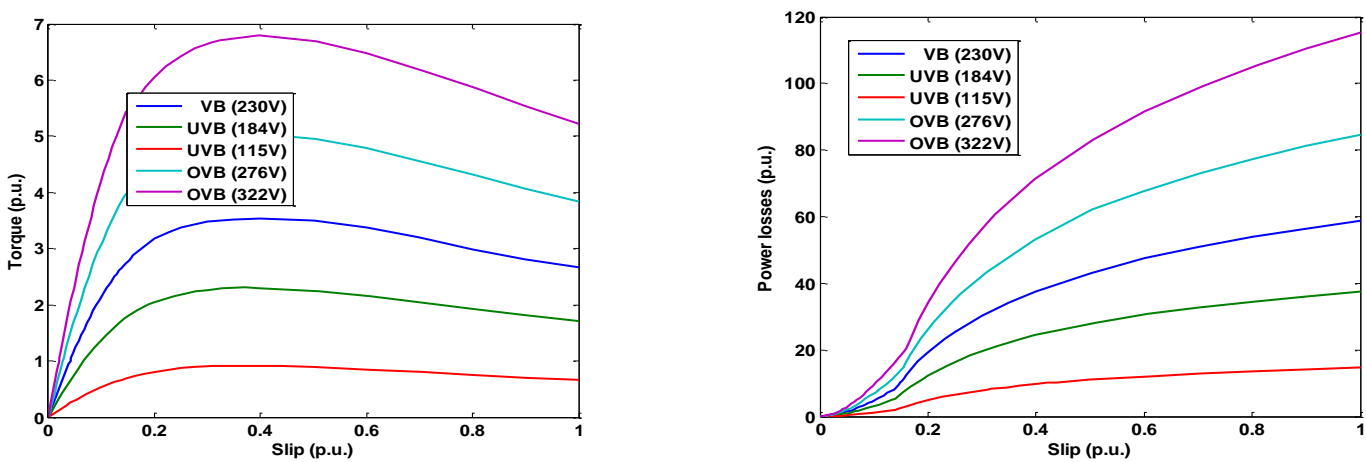

Figure 3. Torque and power losses-slip characteristics under voltage balance disturbance
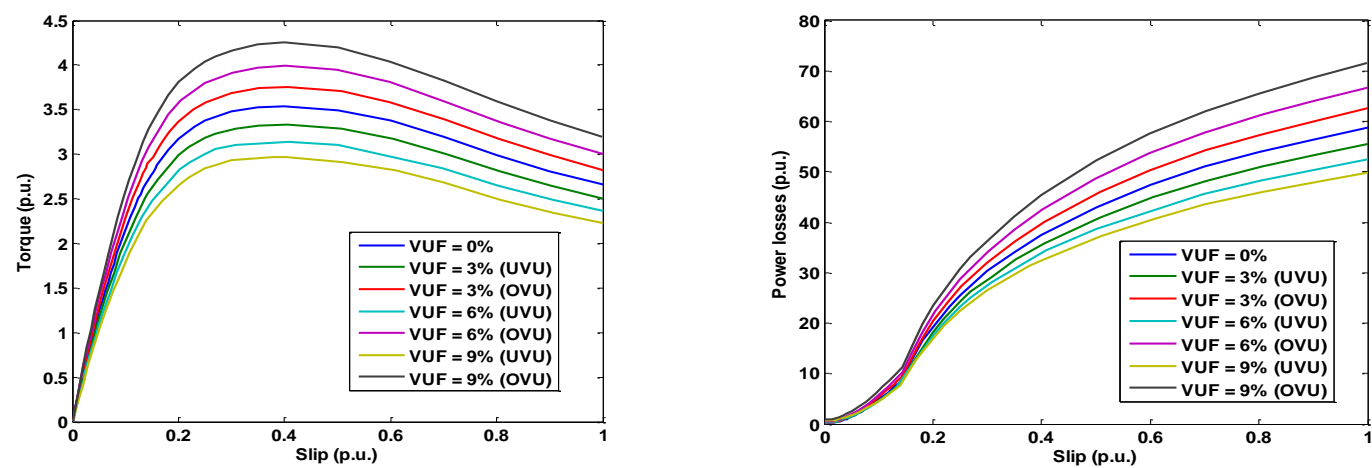

Figure 4. Torque and power losses-slip characteristics under 1-phase voltage unbalance disturbance
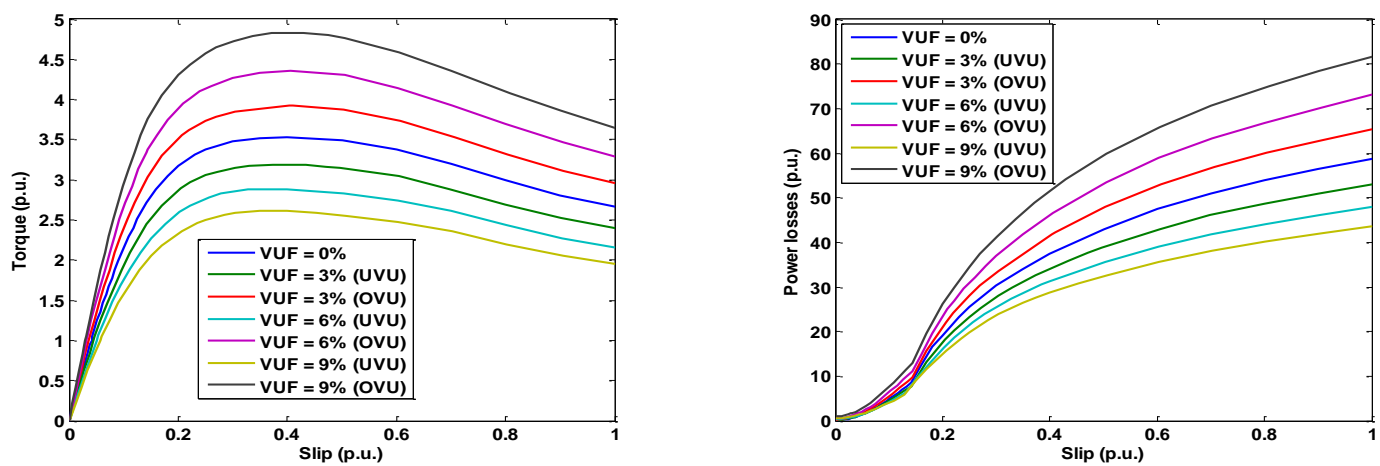

Figure 5. Torque and power losses-slip characteristics under 2-phases voltage unbalance disturbance
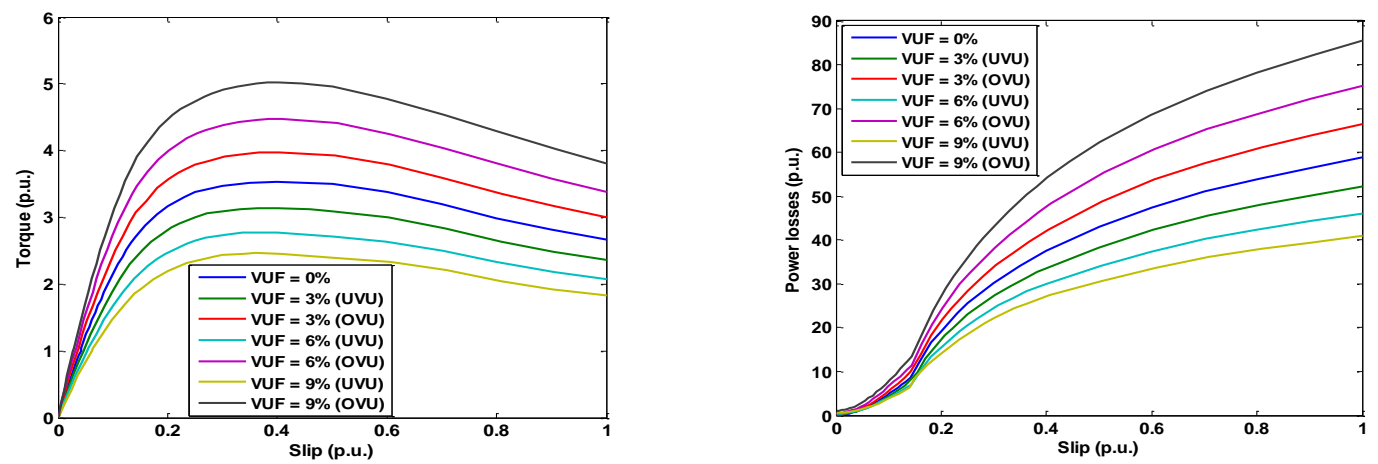

Figure 6. Torque- and power losses-slip characteristics under 3-phases voltage unbalance disturbance 
Table 1 shows the variation ratio of the starting torque and the pullout torque with respect to the motor full-load torque in both voltage disturbance cases; the balance case at VUF $=0$ and the unbalance case at $\mathrm{VUF}=3,6$ and 9. These torques under the balance case are increasing with the increase of the motor terminal voltages. The negative signs in the table, concerning the torque variations with respect to the rated torque under the UVB case of $115 \mathrm{~V}$ phase voltages, refer that the motor under this voltage will not succeed in providing the full-load required. The table also shows how the starting and pullout torques under the UVU disturbance are decreasing with the VUF and the number of failed phases, while they increase under the OVU disturbance.

It's expected that reducing the starting torque under the UVU disturbances could raise the motor starting time and thus increase the related temperature of the motor windings which may exceed the allowable limits. Thus, the motor may not have enough time for cooling during downtime. Further drop in the starting torque might make the motor unable to start. On the other side, reducing the pullout torque of the motor at the UVU disturbances of supply voltages could lead to a narrower margin to operate safely.

Table 1. Ratios of starting and pullout torques under different voltage disturbance conditions

\begin{tabular}{|c|c|c|c|c|c|c|c|c|c|c|c|c|c|c|}
\hline \multirow[b]{2}{*}{$\begin{array}{c}\text { Unbalance } \\
\text { Case }\end{array}$} & \multirow[b]{2}{*}{$\begin{array}{l}\text { Voltage } \\
\text { (V) }\end{array}$} & \multirow{2}{*}{$\begin{array}{c}\text { Failed Phases } \\
\text { VUF } \\
(\%)\end{array}$} & \multicolumn{4}{|c|}{ 1-phase } & \multicolumn{4}{|c|}{ 2-phases } & \multicolumn{4}{|c|}{ 3-phases } \\
\hline & & & $\begin{array}{c}T_{s} \\
(\mathrm{~N} . \mathrm{m})\end{array}$ & $\begin{array}{c}\Delta T_{s} / T_{r} \\
(\%)\end{array}$ & $\begin{array}{c}T_{m} \\
(\mathrm{~N} . \mathrm{m})\end{array}$ & $\begin{array}{c}\Delta T_{w} / T_{r} \\
(\%)\end{array}$ & $\begin{array}{c}T_{s} \\
(\mathrm{~N} . \mathrm{m})\end{array}$ & $\begin{array}{c}\Delta T_{s} / T_{r} \\
(\%)\end{array}$ & $\begin{array}{c}T_{m} \\
(\mathrm{~N} . \mathrm{m})\end{array}$ & $\begin{array}{c}\Delta T_{w} / T_{r} \\
(\%)\end{array}$ & $\begin{array}{c}T_{5} \\
(\mathrm{~N} . \mathrm{m})\end{array}$ & $\begin{array}{c}\Delta T_{s} / T_{r} \\
(\%)\end{array}$ & $\begin{array}{c}T_{m} \\
\text { (N.m) }\end{array}$ & $\begin{array}{c}\Delta T_{w} / T_{r} \\
(\%)\end{array}$ \\
\hline VB & 230 & 0 & & & & & & & & & 127.4 & 166.1 & 169.3 & 253.6 \\
\hline \multirow{2}{*}{ UVB } & 115 & 0 & & & & & & & & & 31.85 & -33.48 & 43.88 & -8.35 \\
\hline & 184 & 0 & & & & & & & & & 81.53 & 70.28 & 110.4 & 130.58 \\
\hline \multirow{3}{*}{ OvB } & 276 & 0 & & & & & & & & & 183.7 & 283.67 & 241.8 & 405.01 \\
\hline & 322 & 0 & & & & & & & & & 250.2 & 422.56 & 325.3 & 579.41 \\
\hline & & 3 & 120 & 150.63 & 159.5 & 233.12 & 114.9 & 139.97 & 152.8 & 219.13 & 112.9 & 135.8 & 150.2 & 213.7 \\
\hline \multirow[t]{3}{*}{ UVU } & & 6 & 113 & 136 & 150.63 & 214.6 & 103.5 & 116.17 & 138.2 & 188.64 & 99.23 & 107.25 & 132.7 & 177.15 \\
\hline & & 9 & 106.4 & 122.22 & 142 & 196.57 & 93.23 & 94.72 & 125.3 & 161.7 & 87.56 & 82.87 & 118 & 146.45 \\
\hline & & 3 & 135 & 181.95 & 179.8 & 275.52 & 141.6 & 195.74 & 188 & 292.65 & 143.8 & 200.33 & 190.5 & 297.87 \\
\hline \multirow[t]{2}{*}{ OVU } & & 6 & 143.8 & 200.33 & 191.2 & 299.33 & 157.4 & 228.74 & 208.8 & 336.09 & 162 & 238.35 & 214.1 & 347.16 \\
\hline & & 9 & 152.8 & 219.13 & 203.5 & 325.02 & 174.4 & 264.24 & 231.4 & 383.29 & 182.4 & 280.95 & 240.3 & 401.88 \\
\hline
\end{tabular}

\section{CONCLUSION}

This paper presents an estimation of the steady-state performance of a three-phase IM under disturbed voltage supply. The estimation results demonstrate how during unbalanced voltage operations, the IM dissipates extra energy fed from the voltage supply, feeding the motor power losses. These losses increase considerably with unbalance voltage degree, leading to an important decrease in the motor efficiency. The losses are smaller in over voltage condition than under voltage for the lower range of voltage unbalance. The higher the unbalance subjected to the IM, the more the efficiency decreases. Further, the efficiency is higher in over voltage condition than under voltage for the lower range of voltage unbalance. The motor has higher efficiency with single-phase unbalanced voltage rather than two and three-phase unbalance. The voltage unbalance degree has a negligibly small effect on the required reactive power and power factor in under voltage while it affects badly in over voltage condition, especially when all three phases of the motor are disturbed. The power factor is found be lower in the condition of over voltage than under voltage for any unbalance degree.

The motor rated slip is inversely (speed is direct) proportional to the degree of the applied phase voltages and greatly affected by the three-phase voltage unbalance in comparison with one and two-phases of unbalance. The slip (speed) values are more affected in under voltage condition than over voltage. The disturbed voltages on the motor terminals result in changing the torque-slip characteristics and thus the motor operating point. The motor needs more starting and pullout torques when operating in under voltage single-phase rather than two and three-phase disturbance, while these torques are better in over voltage three-phase rather than two and single-phase disturbances, respectively. The effect of voltage unbalance in increasing the motor losses is considerably higher in over voltage than under voltage disturbance. This effect becomes much higher at high loads. The losses rise with increasing the number of failed phases in over voltage while drop in under voltage condition.

\section{REFERENCES}

[1] C. Bayliss, B. Hardy, "Transmission and Distribution Electrical Engineering," 4th Edition, Newnes Elsevier Science Group, Inc., 2011.

[2] C. Brunner, P. Waide, M. Jakob, "Harmonized standards for motors and systems-Global progress report and outlook," Proc. of Energy Efficiency in Motor Driven Systems (EEMODS '11), Alexandria, Virginia, Sep. 12-14, 2011.

[3] Chakrabarti, S. Debnath, "Electrical Machines," McGraw-Hill Education (India) Private Limited, 1st Edition, 2015. 
[4] W.H. Kersting, W.H. Phillips, "Phase frame analysis of the effects of voltage unbalance on induction machines," IEEE Transactions on Industry Applications, vol. 33, no. 2, pp. 415-420, 1997.

[5] C.-Y. Lee, "Effects of unbalanced voltage on operation performance of a three-phase induction motor," IEEE Transactions on Energy Conversion, vol. 14, no. 2. pp. 202-208, 1999.

[6] A.M.S. Mendes, E.C. Quispe, X.M.L. Fernandez, A.J.M. Cardoso, "Influence of the positive sequence voltage on the temperature of three-phase induction motors," XIX Int. Conf. on Elect. Machines-ICEM 2010 Italy, 6-8 Sep. 2010.

[7] E.C. Quispe, I.D. López, F.J.T.E. Ferreira, V. Sousa, "Unbalanced Voltages Impacts on the Energy Performance of Induction Motors," Int. Journal of Electrical \& Computer Eng. (IJECE), Vol. 8, No. 3, pp. 1412-1422, 2018.

[8] C.A. Reineri, J.C. Gomez, E.B. Balaguer, M.M. Morcos, "Experimental study of IM performance with unbalanced supply, Electric Power Components and Systems," Electric Power Components and Systems, vol. 34, no. 7, pp. 817-829, 2006.

[9] J.Faiz, H. Ebrahimpour, P. Pillay, "Influence of unbalanced voltage supply on efficiency of three phase squirrel cage induction motor and economic analysis," Energy Conversion and Management, vol. 47, no. 3, pp. 289-302, 2006.

[10] J.H. Dymond, N. Stranges, "Operation on Unbalanced Voltage: One Motor's Experience and More," IEEE Transactions on Industry Applications, vol. 43, no. 3, pp. 829-837, 2007.

[11] H.F. Farahani, H.R. Hafez, D. Habibinia, A.R. Jalilean, A. Shoulaei, "Investigation of unbalance supplying voltage on the thermal behavior of squirrel cage induction motor using monitoring system," 42nd International Universities Power Engineering Conference, Brighton UK, 4-6 Sep. 2007.

[12] P. Gnacinski, "Effect of unbalance voltage on winding temperature, operation life and load carrying capacity of induction machine," Energy Conversion and Management, vol. 49, no. 4, pp. 761-770, 2008.

[13] G.R. Bossio, C.H.De. Angelo, P.D. Donolo, A.M. Castellino, G.O. Garcia, "Effects of voltage unbalance on IM power, torque and vibrations," IEEE International Symposium on Diagnostics for Electric Machines, Power Electronics and Drives, 31 Aug.-3 Sept. 2009.

[14] D. Mirabbasi, G. Seifossadat, M. Heidari, "Effect of unbalanced voltage on operation of induction motors and its detection," International Conference on Electrical and Electronics Engineering - ELECO 2009, 5-8 Nov. 2009.

[15] A.B.F. Neves, A.d.L.F. Filho, M.V.B.d. Mendon, Mendon, "Effects of voltage unbalance on torque and efficiency of a three-phase induction motor," 16th Int. Conf. on Harmonics and Quality of Power, 25-28 May 2014.

[16] S.Gupta, P. Thakur, A.K. Singh, "Effects of voltage unbalance on normalized performance parameters," IEEE Students Conference on Engineering and Systems (SCES), 6-8 Nov. 2015.

[17] X.M.L.- Fernández, A.P. Coimbra, J.A.D. Pinto, C.L. Antunes, M.P. Donsión, "Thermal analysis of an induction motor fed by unbalanced power supply using a combined Finite Element-Symmetrical Components formulation," in Proc. 1998 Int. Conf. on Power System Tech., POWERCON'98, Beijing, China, 1 (1998) 620-624, $18-21$ August.

[18] Y.-h. Wang, "An analytical study on steady-state performance of an induction motor connected to unbalanced three-phase voltage," IEEE Power Engineering Society Winter Meeting, Conference Proceedings, 23-27 Jan. 2000.

[19] Y.J. Wang, "Analysis of effects of three phase voltage unbalances on induction motors with emphasis on the angle of the complex voltage unbalance factor," IEEE Trans. on EC, vol. 16, no. 3, pp. 270-275, 2001.

[20] J. Faiz, H. Ebrahimpour, P. Pillay, "Influence of unbalanced voltage on the steady-state performance of a three-phase squirrel-cage induction motor," IEEE Trans. on Energy Conversion, vol. 19, no. 4, pp. 657-662, 2004.

[21] S.-Y. Huang, Y.-h. Wang, "Analysis of a three-phase induction motor under voltage unbalance using the circle diagram method," Int. Conf. on Power System Technology, PowerCon 2004, Singapore, 21-24 Nov. 2004.

[22] K.S. Sandhu, V. Chaudhary, "Steady state modelling of induction motor operating with unbalanced supply system," WSEAS Transactions on Circuits and Systems, vol. 8, no. 2, pp. 197-206, 2009.

[23] Jalilean, R. Roshanfekr, "Analysis of three-phase induction motor performance under different voltage unbalance conditions using simulation and experimental results," Elec. Power Comp. \& Sys., vol. 37, no. 3, pp. 300-319, 2009.

[24] S. Eftekhari, M.O. Sadegh, "The effect of load modelling on phase balancing in distribution networks using search harmony algorithm," Int. Journal of Electrical \& Computer Eng. (IJECE), Vol. 9, No. 3, pp. 1461-1471, 2019.

[25] A.H. Abed, J. Rahebi, H. Sajir, A. Farzamnia, "Protection of sensitive loads from voltages fluctuations in Iraqi grids by DVR," IEEE 2nd Int. Conf. on Automatic Control and Intelligent Systems (I2CACIS), 21 -21 Oct 2017.

[26] R. kianinezhad, G. Seifossadat, M. Heidari, M. Monadi, "Effects of Distribution Network Unbalance Voltage Types in Respect to Identical Unbalance Factor on the Induction Motors," Int. Conf. on Electrical and Electronics Engineering-ELECO 2009, IEEE 5-8 Nov. 2009.

[27] Atyia, T. H. "Control Techniques of Torque Ripple Minimization for Induction Motor," Tikrit Journal of Engineering Sciences, Vol.25, No.4. pp. 57-63, 2018.

[28] P. Pillay, M. Manyage, "Definitions of voltage unbalance," IEEE Power Eng. Review, vol.21, no.5, pp. 49-51, 2001. 


\section{BIOGRAPHIES OF AUTHORS}
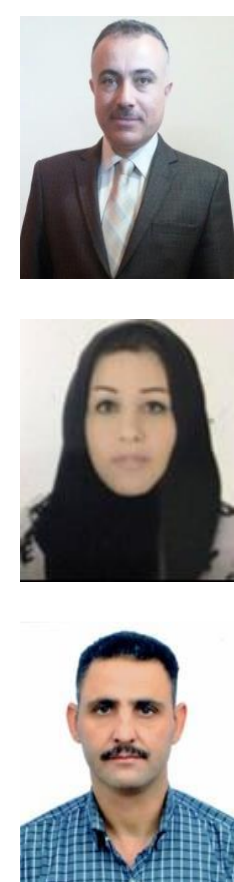

Jamal A.-K. Mohammed was born in Iraq, in 1967. He obtained his B.Sc. of Electrical Engineering degree in 1996 and his M.Sc. of Electrical Engineering degree in 2002 from University of Technology, Baghdad. His Ph.D. degree was awarded in 2007 by University of Technology, Iraq-Baghdad. He is an Assistant Professor at the Department of Electromechanical Engineering, University of Technology. His research interests include electrical machines, electrical drives, power electronics, Elevators, and renewable energy (solar). He has published close to 30 papers and has supervised several M.Sc. and Ph.D. thesis.

Sahar R.AL-Sakini was born in Iraq, in 1965. She obtained her B.Sc. in Electrical Engineering in 1987 and her M.Sc. in 1999 from University of Technology, Baghdad. Her Ph.D. degree was awarded in 2003 by University of Technology, Baghdad-Iraq. Currently she is a lecturer at the Department of Electromechanical Engineering, University of Technology. She published many research in power system and renewable energy.

Arkan Ahmed Hussein received his PhD in Electrical Engineering from the Department of Electrical Engineering, Jamia Millia Islamia, New Delhi, India, in 2015. He obtained his BSc and MSc in Electrical Engineering from the University of Technology, Iraq, in 1998 and 2005, respectively. Currently, he is an Assistant Professor in the Tikrit University, Iraq. His research interests include power system operation and control, automatic generation control, soft computing techniques in power systems and HVDC transmission systems. 